\title{
PENGARUH LOCUS OF CONTROL DAN SIKAP REKAN KERJA TERHADAP KINERJA AUDITOR (Studi Pada Kantor Inspektorat se-Luwu Raya) Iriansyah $^{1)}$, Halim Usman ${ }^{2)}$, Duriani ${ }^{3)}$ \\ Jurusan Akuntansi, Fakultas Ekonomi dan Bisnis, Universitas Muhammadiyah Palopo Email:1'Iriansyaha2@gmail.com \\ ${ }^{2}$ halim.stiemlecture@gmail.com
}

\begin{abstract}
ABSTRAK
Penelitian ini bertujuan untuk mengetahui dan menganalisis pengaruh Locus Of Control dan sikap rekan kerja terhadap kinerja auditor di Kantor Inspektorat se-Luwu Raya (Kota Palopo, Kabupaten Luwu, Kabupaten Luwu Utara dan Kabupaten Luwu Timur). Metode penelitian ini menggunakan pendekatan survey dengan memberikan daftar pernyataan di Kantor Inspektorat se-Luwu Raya (Kota Palopo, Kabupaten Luwu, Kabupaten Luwu Utara dan Kabupaten Luwu Timur). Kuesioner yang dibagikan kepada responden sebanyak 91 eksamplar dan kuesioner yang dikembalikan sebanyak 70 eksamplar. Penelitian ini menggunakan pendekatan kuantitatif dan menggunakan analisis regresi linear berganda (Multiple Regression Analysis) dengan tambahan uji validitas dan uji reliabilitas. Penelitian ini juga menggunakan pengujian hipotesis berupa uji koefisien determinasi, uji persial $(t)$ dan uji simultan $(F)$. Hasil penelitian ini menunjukkan bahwa Locus Of Control berpengaruh signifikan dan sikap rekan kerja tidak berpengaruh signifikan terhadap kinerja auditor di Kantor Inspektorat se-Luwu Raya (Kota Palopo, Kabupaten Luwu, Kabupaten Luwu Utara dan Kabupaten Luwu Timur).
\end{abstract}

Kata Kunci: Locus Of Control, Sikap Rekan Kerja dan Kinerja Auditor

\section{ABSTRACT}

This study aims to determine and analyze the effect of Locus Of Control and coworkers' attitudes on auditor performance in Inspectorate Offices throughout Luwu Raya (Palopo City, Luwu Regency, North Luwu Regency and East Luwu Regency). This research method uses a survey approach by giving a list of statements in the Inspectorate Office throughout Luwu Raya (Palopo City, Luwu Regency, North Luwu Regency and East Luwu Regency). Questionnaires were distributed to respondents as many as 91 exams and questionnaires were returned as many as 70 exams. This study uses a quantitative approach and uses multiple linear regression analysis (Multiple Regression Analysis) with additional validity and reliability tests. This study also uses hypothesis testing in the form of a coefficient of determination test, persial test $(t)$ and simultaneous test $(F)$. The results of this study indicate that the Locus Of Control has a significant effect and the attitude of coworkers does not significantly influence the performance of auditors in the Inspectorate Office throughout Luwu Raya (Palopo City, Luwu Regency, North Luwu Regency and East Luwu Regency).

Keywords: Locus Of Control, Attitudes of Colleagues and Auditor Performance

\section{PENDAHULUAN}

Pengawasan intern yang dilakukan oleh Aparat Pengawasan Intern Pemerintah (APIP) yang terdapat dalam Peraturan Pemerintah Republik Indonesia No. 60 Tahun 2008 Pasal 1 ayat 3 tentang Sistem Pengendalian Intern Pemerintah yang terdiri dari audit, reviw, evaluasi, pemantauan dan kegiatan pengawasan lainnya, Pengawasan bersifat membantu agar sasaran yang ditetapkan organisasi dapat tercapai, dan secara dini menghindari terjadinya penyimpangan pelaksanaan, penyalahgunaan wewenang, pemborosan dan kebocoran.

Salah satu unit yang melakukan audit/pemeriksaan terhadap pemerintah daerah adalah inspektorat daerah mempunyai, tugas menyelenggarakan kegiatan pengawasan umum 
pemerintah daerah dan tugas yang diberikan kepala daerah, sehingga dalam tugasnya inspektorat sama dengan auditor internal.

Audit internal adalah audit yang dilakukan oleh unit pemeriksa yang merupakan bagian dari organisasi yang diawasi oleh pemerintah (Widyastuti, 2017). Audit internal membantu organisasi dalam mencapai tujuan dengan menerapkan pendekatan yang sistematis dan berdisiplin untuk mengevaluasi kontrol dan pengelolaan organisasi. Selain itu Audit Internal merupakan suatu langkah awal dalam mengurangi kecurangan dan meningkatkan pengendalian internal (Rahmawati dan Zikra, 2019). Audit internal diharapkan dapat membuat kinerja perusahaan lebih efektif, efisien dan ekonomis. Melalui pengawasan internal yang baik dapat diketahui apakah suatu perusahaan pemerintah telah melaksanakan kegiatan sesuai dengan tugas dan fungsinya secara efektif dan efisien, serta sesuai dengan rencana, kebijakan perusahaan yang telah ditetapkan, dan ketentuan perundang-undangan yang berlaku. Sehingga perlu ditingkatkan kinerja para auditor agar dapat membantu tercapainya tujuan perusahaan. Kinerja adalah suatu hasil kerja yang dicapai seseorang dalam melaksanakan tugas-tugas yang dibebankan kepadanya, yang didasarkan atas kecakapan, pengalaman, dan kesungguhan serta waktu. Kinerja auditor merupakan perwujudan kerja yang dilakukan dalam rangka mencapai hasil kerja yang lebih baik atau lebih menonjol ke arah tercapainya tujuan organisasi. Pencapaian kinerja auditor yang lebih baik harus sesuai dengan standar dan kurun waktu tertentu (Komalasari, 2017).

Berkaitan dengan pentingnya pengalaman dan Locus Of Control, maka perlu diperhatikan oleh setiap auditor internal, khususnya pada instansi pemerintah daerah yang menjadi objek penelitian yaitu pada Kantor Inspektorat se-Luwu Raya (Kota Palopo, Kabupaten Luwu, Kabupaten Luwu Utara dan Kabupaten Luwu Timur), karena pengalaman audit dan Locus Of Control merupakan aspek personalitas yang akan mempengaruhi perilaku individu, Semakin berpengalaman seseorang melakukan pekerjaan yang sama, maka akan semakin terampil dan semakin cepat dalam menyelesaikan pekerjaan tersebut hal ini menjadi sebagai acuan kedepan dalam menghadapi masalah berkaitan dengan audit (Rahmawati dan Halim, 2016) Selain itu Locus Of Control pada auditor internal bisa memengaruhi perilaku individu dalam pengambilan keputusan, keberhasilan dalam pekerjaan mereka dan berkaitan dengan penggolongan individu.

Selain Locus Of Control yang termasuk ke dalam faktor individual, yang dapat mempengaruhi peningkatan kinerja auditor. Terdapat faktor lain yaitu, faktor situasional yang mempengaruhi kinerja yaitu, sikap antar rekan kerja. Menurut Nurmatias (2015), terdapat 
berbagai faktor kinerja, antara lain yaitu jumlah dan komposisi dari kompensasi yang diberikan, penempatan kerja yang tepat, pelatihan dan promosi, rasa aman di masa depan (dengan adanya pesangon dan sebagainya), hubungan dengan rekan kerja, hubungan dengan pemimpin.

Rekan kerja di butuhkan untuk bagaimana suatu kegiatan atau pekerjaan yang di lakukan dalam organisasi/pemerintahan itu dapat berjalan efektif. Seorang/sekelompok orang yang bekerja dalam satu organisasi baik yang bekerja secara individu maupun kelompok. Dalam pencapaian tujuan organisasi/perusahaan sikap rekan kerja mempunyai peran yang cukup penting terhadap suatu kualitas dan kinerja auditor, karena rekan kerja merupakan bagian yang tak terpisahkan dalam hubungan kerja di suatu organisasi. Ada beberapa indikator mengenai sikap rekan kerja yaitu memiliki kompetensi yang sehat, saling menghormati, bekerja sama dengan menyelesaikan masalah, dan memiliki suasana kekeluargaan (Permana, 2016).

Berdasarkan fenomena yang diungkapkan oleh Badan Pemeriksa Keuangan (BPK) atas Laporan hasil pemeriksaan Pemerintah Kota Palopo, telah ditemukan adanya beberapa penyimpangan dalam proses penyelenggaraan pemerintah diantaranya yaitu, penyalahgunaan dana kas daerah melalui pencairan dana kas daerah tanpa menggunakan Surat Perintah Pencairan Dana (SP2D), serta adanya rekayasa rekening koran dan surat jawaban konfirmasi Bank untuk menutupi transaksi kas yang dilakukan tanpa melalui mekanisme Anggaran Pendapatan Belanja Derah (APBD). Meskipun demikian, Pemerintah Kota Palopo meraih opini Wajar Dengan Pengecualian dari BPK pada tahun 2014 (BPK RI Sul-Sel, 2014) (Sari, 2016).

Dari hasil pemeriksaan tersebut diatas, tidak menunjukkan fungsi pemeriksaan auditor internal yang seharusnya dalam rangka peningkatan kinerja auditor internal. Dimana untuk dapat menjalankan fungsi ini seorang auditor harus memiliki independensi dan kompetensi yang dapat mempengaruhi kinerja seorang auditor internal. Inspektorat seperti tak hadir mencegah maraknya penyimpangan. Padahal, inspektorat seharusnya menjadi alat deteksi dini. Posisi inspektorat yang melekat di setiap instansi pemerintahan memungkinkan mereka mengawasi dan melakukan pengendalian secara detail penggunaan keuangan negara untuk mencegah penyimpangan.

Sehingga banyak kalangan menilai, gagal menyalanya alarm deteksi dini inspektorat merupakan hal yang lumrah. Sebab, selama ini inspektorat hanya bawahan menteri/kepala lembaga dan kepala daerah. Tidak jarang peringatan yang dikeluarkan oleh inspektorat diabaikan begitu saja, bahkan bisa jadi lebih buruk, mereka yang memperingatkan justru kerap dianggap sebagai musuh dalam selimut. Sanksinya, bisa saja dibebastugaskan, dimutasi, atau karirnya dipersulit. Akhirnya mau tidak mau inspektorat harus menurut ke pimpinan. Sehingga 
tidak ada lagi independensi bagi inspektorat dalam melaksanakan tugas dengan maksimal. Padahal, independensi menjadi salah satu unsur penting bagi pengawas auditor.

Auditor internal pemerintah sering mendapat sorotan tajam terkait dengan kinerjanya yang cenderung menurun, terutama pada pemerintah-pemerintah daerah. Khikmah (2009), Inspektorat dahulu Badan Pengawas Daerah (Bawasda) merupakan bagian dari jabatan fungsional audit dan aparat pengawas internal pemerintah yang berada ditingkat Kabupaten, Kota, dan Provinsi, Inspektorat dapat menjadi ujung tombak untuk meningkatkan akuntabilitas publik dan transparansi dalam pengelolaan keuangan di daerah. Peran inspektorat ini menjadi sangat penting karena kebijakan otonomi daerah dan desentralisasi menempatkan daerah, terutama Provinsi, Kabupaten dan Kota sebagai pelaksana terdepan pembangunan. Daerah akan banyak menerima limpahan dana dari anggaran pendapatan dan belanja negara (APBN) seperti dana alokasi umum (DAU) dan dana alokasi 3 khusus (DAK). Oleh karena itu, upaya peningkatan efektivitas inspektorat untuk pengawasan keuangan di daerah menjadi krusial.

Penelitian ini berupaya menerapkan good governance dengan menjadikan akuntabilitas sebagai salah satu faktor pendukung, sehingga auditor internal pemerintah menjadi sosok penting dalam upaya ini. Karena itu, peneliti tertarik untuk melakukan penelitian lebih lanjut terhadap auditor internal yang bekerja di Kantor Inspektorat se-Luwu Raya (Kota Palopo, Kabupaten Luwu, Kabupaten Luwu Utara dan Kabupaten Luwu Timur) dengan memasukkan variabel Locus Of Control dan Sikap Rekan Kerja sebagai variabel yang memengaruhi kinerja auditor. Adapun yang menjadi pertimbangan peneliti melakukan penelitian lebih lanjut terhadap auditor internal yang bekerja di Inspektorat karena pada dasarnya salah satu yang menjadi tugas pokok dan fungsi ndari inspektorat dalam hal ini auditor internal pemerintah yakni pengawasan, pengendalian, dan pemeriksaan.

\section{LANDASAN TEORI}

\section{Teori Atribusi (Attribution Theory)}

Menurut Heider (1958) pencetus teori atribusi, yang merupakan teori yang menjelaskan tentang perilaku seseorang. Apakah perilaku itu disebabkan oleh faktor disposisional (faktor dalam/internal), misalnya sifat, karakter, sikap dsb, ataukah disebabkan oleh keadaan ekternal, misalnya tekanan situasi atau keadaan tertentu yang memaksa seseorang melakukan perbuatan tertentu (Luthans 2005: 173). 


\section{Locus Of Control}

Beberapa penelitian membedakan orientasi Locus Of Control menjadi dua, yakni Locus Of Control internal dan Locus Of Control eksternal, hal ini dijelaskan bahwa individu dengan Locus Of Control internal cenderung menganggap bahwa keterampilan (skill), kemampuan (ability), dan usaha (effort) lebih menentukan apa yang mereka peroleh dalam hidup. Individu dengan Locus Of Control eksternal cenderung menganggap hidup mereka lebih ditentukan oleh kekuatan dari luar diri mereka, seperti nasib, takdir, dan keberuntungan (Fadila, 2016).

\section{Sikap Rekan Kerja}

Sikap rekan kerja adalah tindakan perilaku seorang atau sekelompok orang yang bekerja dalam satu organisasi baik yang bekerja secara individu maupun berkelompok yang memiliki dua peran yaitu sebagai mahluk individu dan mahluk sosial, manusia harus memiliki kemampuan untuk melakukan interaksi dengan lingkungannya, karena dengan berinteraksi manusia dapat tumbuh dan berkembang sewajarnya sebagai manusia. Yang dapat di ukur dengan melihat kompetensi yang sehat, saling menghormati, bekerja sama dengan menyelesaikan masalah, dan menciptakan suasana kekeluargaan. Interaksi merupakan proses dimana orangorang berkomunikasi saling mempengaruhi dalam pikiran dan tindakan (Dewi, 2017).

\section{Kinerja Auditor}

Secara etimologi, kinerja berasal dari kata Job Performance atau Actual Performance (prestasi kerja atau prestasi sesungguhnya yang dicapai oleh seseorang. Menurut Mangkunegara (2010: 9) kinerja adalah prestasi kerja, prestasi sesungguhnya atau suatu hasil kerja secara kualitas dan kuantitas yang dicapai oleh seseorang dalam melaksanakan tugastugas sesuai dengan tanggungjawab yang diberikan kepadanya. Hasil ini dicapai berdasarkan atas kecakapan, kemampuan, dan kesungguhan serta waktu. Kesuksesan yang dicapai seseorang dalam melaksanakan suatu pekerjaan disebut kinerja. Kesuksesan yang dimaksud tersebut ukurannya tidak dapat disamakan pada semua orang, namun lebih merupakan hasil yang dicapai oleh seseorang menurut ukuran yang berlaku sesuai dengan pekerjaan yang ditekuni.

\section{METODE PENELITIAN}

Jenis data yang digunakan dalam penelitian ini adalah data primer yang sumber datanya diperoleh melalui penyebaran kuesioner kepada auditor internal yang bekerja di Kantor Inspektorat se-Luwu Raya (Kota Palopo, Kabupaten Luwu, Kabupaten Luwu Utara dan Kabupaten Luwu Timur) Adapun populasi dalam penelitian ini meliputi seluruh auditor internal 
yang bekerja pada Kantor Inspektorat seLuwu Raya yang berjumlah 91 auditor, terdiri dari 16 auditor di Kantor Inspektorat Kota Palopo, 14 auditor di Kantor Inspektorat Kabupaten Luwu, 35 auditor di Kantor Inspektorat Kabupaten Luwu Utara dan 26 auditor di Kantor Inspektorat Kabupaten Luwu Timur).

Sampel dalam penelitian ini adalah auditor internal yang menjawab kuesioner yang disebar peneliti pada Kantor Inspektorat se-Luwu raya (Kota Palopo, Kabupaten Luwu, Kabupaten Luwu Utara dan Kabupaten Luwu Timur). Metode pemilihan sampel dalam penelitian ini adalah metode sampling jenuh atau sensus dimana semua anggota populasi dijadikan sampel karena pengambilan sampel relative kecil.

\section{HASIL PENELITIAN DAN PEMBAHASAN}

\section{Pengaruh Locus Of Control terhadap Kinerja Auditor.}

Berdasarkan analisis hasil penelitian menunjukkan bahwa Locus Of Control berpengaruh secara signifikan terhadap kinerja auditor di Kantor Inspektorat seLuwu Raya (Kota Palopo, Kabupaten Luwu, Kabupaten Luwu Utara dan Kabupaten Luwu Timur), secara persial Locus Of Control berpengaruh secara signifikan terhadap kinerja auditor. Penelitian ini sejalan dengan teori atribusi dimana teori atribusi menjelaskan cara pribadi menilai orang lain bergantung pada makna yang diberikan pribadi tersebut ke perilaku tertentu. Dimana dalam melaksanakan tanggung jawabnya salah satu hal yang mempengaruhi auditor yakni faktor individual dari auditor itu sendiri, faktor individual yang dimaksudkan ialah Locus Of Control

Hal ini terjadi karena auditor yang memiliki Locus Of Control internal mempunyai sifat yang lebih bertanggung jawab, dan segala sesuatu yang baik dan buruk tergantung pada diri kita sendiri. Orang-orang yang termasuk dalam internal Locus Of Control mempunyai persepsi bahwa apa yang terjadi pada diri mereka bergantung pada apa yang telah dilakukan oleh diri mereka sendiri. Sedangkan yang memiliki Locus Of Control eksternal mempunyai cara pandang segala sesuatu yang terjadi karena faktor luar seperti keberuntungan, kesempatan, dan takdir. Hasil penelitian ini juga sejalan dengan penelitian yang dilakukan oleh Saputra (2012), Putra (2016), dan Shauqi (2018) yang memiliki pengaruh secara signifikan terhadap kinerja Auditor. Namun penelitian ini tidak sejalan dengan hasil penelitian yang dilakukan oleh Azhar L (2013) yang berpendapat bahwa Locus Of Control tidak berpengaruh signifikan terhadap kinerja auditor. 


\section{Pengaruh sikap rekan kerja terhadap kinerja Auditor.}

Berdasarkan hasil dari analisis regresi berganda menunjukkan bahwa sikap rekan kerja tidak berpengaruh secara signifikan terhadap kinerja auditor di Kantor Inspektorat se-Luwu Raya (Kantor Palopo, Kabupaten Luwu, Kabupaten Luwu Utara dan Kabupaten Luwu Timur), secara persial sikap rekan kerja tidak berpengaruh signifikan terhadap kinerja auditor. Hal ini dikarenakan sikap rekan kerja bukanlah hal pokok dalam menentukan hasil kerja seorang auditor.

Hasil penelitian menunjukkan sikap rekan kerja tidak berpengaruh terhadap kinerja auditor hal ini dikarnakan sikap rekan kerja hanya dibutuhkan sementara untuk membantu menyelesaikan tugas lapangan saja seperti mencari bukti audit. Kejadian-kejadian atau perilaku yang dilakukan oleh setiap rekan dalam sebuah organisasi merupakan cerminan dari lingkungan dan kondisi sosial tempat dia bekerja, sehinggah hal ini sesuai dalam teori atribusi yang dijelaskan bahwa perilaku seseorang dipengaruhi oleh dua faktor yaitu faktor internal dan faktor eksternal. Apabila seorang rekan melakukan tindakan kejahatan atau tindakan yang merugikan bagi organisasi maka harus dapat cepat mendeteksi penyebab dari tindakan tersebut, karena bisa menjadi suatu motivasi atau menjadi penyebab seseorang melakukan hal merugikan di tempat dia bekerja seperti dari lingkungan, dan nilai sosial dari organisasi sendiri atau dikarenakan faktor yang ada dari pribadi seseorang.

Hasil penelitian ini sejalan dengan penelitian yang dilakukan oleh Panjaitan (2014) dan Dewi (2017) yang menemukan bahwa sikap rekan kerja tidak berpengaruh terhadap kinerja auditor dikarenakan, auditor menjunjung tinggi sikap obyektivitas dalam bekerja dan memiliki keyakinan terhadap diri mereka sendiri untuk menyelesaikan pekerjaan mereka tanpa harus dipengaruhi oleh sikap rekan kerjanya. Auditor tidak terpengaruh dengan hal-hal yang tidak memiliki hubungan dengan pekerjaan. Karna kinerja auditor dapat dipengaruhi juga oleh beberapa hal seperti kualitas laporan keuangan yang diberikan oleh perusahaan yang bersangkutan, integritas auditor, kejujuran auditor, ketidakberpihakan auditor kepada siapapun. Sehingga sikap rekan kerja hanya dibutuhkan sementara untuk membantu menyelesaikan tugas lapangan saja, seperti mencari bukti audit dan lain-lain. Namun penelitian ini tidak sejalan dengan hasil penelitian yang dilakukan oleh Maulita (2015) dan Permana (2016) yang berpendapat bahwa sikap rekan kerja berpengaruh signifikan terhadap kinerja auditor. 


\section{KESIMPULAN DAN SARAN}

\section{Kesimpulan}

Berdasarkan hasil analisis, pengujian hipotesis dan pembahasan yang telah dilakukan yaitu mengenai pengaruh Locus Of Control dan sikap rekan kerja terhadap kinerja auditor pada Kantor Inspektorat se-Luwu Raya (Kota Palopo, Kabupaten Luwu, Kabupaten Luwu Utara dan Kabupaten Luwu Timur) maka dapat disimpulkan bahwa; 1). Locus Of Control berpengaruh signifikan terhadap kinerja auditor pada Kantor Inspektorat se-Luwu Raya (Kota Palopo, Kabupaten Luwu, Kabupaten Luwu Utara dan Kabupaten Luwu Timur). Sehingga hipotesis pertama dinyatakan diterima. 2). Sikap rekan kerja tidak berpengaruh secara signifikan terhadap kinerja auditor auditor pada Kantor Inspektorat se-Luwu Raya (Kota Palopo, Kabupaten Luwu, Kabupaten Luwu Utara dan Kabupaten Luwu Timur). Sehingga hipotesis kedua dinyatakan ditolak.

\section{Saran}

Berdasarkan simpulan dan keterbatasan penelitian diatas maka penulis memberikan saran antaran lain; 1). Diharapkan penelitian ini dapat digunakan sebagai sumber referensi penelitian selanjutnya yang memiliki topik dan tema yang sama. 2). Selain menggunakan kuesioner secara tertulis bisa ditambahkan dengan menggunakan wawancara atau interview. Selain itu, untuk peneliti selanjutnya diharapkan melaksanakan penelitian dengan responden yang lebih luas agar penelitian dapat digunakan secara universal. Serta peneliti selanjutnya diharapkan menambah variabel penelitian, agar dapat diketahui adanya variabel lain yang mempengaruhi kinerja auditor.

\section{DAFTAR PUSTAKA}

.Azhar L, Al. 2013. Pengaruh Konflik Peran, Ketidakjelasan Peran, Kesan Ketidakpastian Lingkungan, Locus Of Control Dan Motivasi Kerja Terhadap Kinerja Auditor (Studi Empiris Pada Kantor Akuntan Publik Di Pekanbaru, Padang Dan Batam). Jurnal Ekonomi, Vol: 21, No:4, Hal: 1-15. Darendehe, Albert. 2013. Gaji, Kepemimpinan, Dan Sikap Rekan Kerja Pengaruhnya Terhadap Kinerja Karyawan Pt. Askes (Persero) Cabang Manado. Jurnal EMBA, Vol: 1, No: 4, Hal: 22-30.

Dewi, Amin Priyatna. 2017. Pengaruh Locus Of Control Dan Sikap Rekan Kerja Terhadap Kinerja Auditor Dengan Etika Kerja Islam Sebagai Variabel Moderating (Studi Empiris Pada Kantor Akuntan Publik Di Solo Dan Yogyakarta). Skripsi. Surakarta. Program Pascasarjana Institut Agama Islam Negeri Surakarta.

Heider, Fritz. 1958. The Psychology of Interpersonal Relations, New York: Wiley. Ida Dan Cinthia Yohana Dwinta. 2010. Pengaruh Locus Of Control , Financial Knowledge, Income Terhadap Financial Management Behavior. Jurnal Bisnis Dan Akuntansi, Vol: 12, No: 3, Hal: 131-144. 
Khikmah, N.S. dan Edi Priyanto.2009. Komitmen Organisasi, Locus Of Control , dan Kompleksitas Tugas Terhadap Kinerja Auditor Internal. Jurnal analisis bisnis ekonomi, Vol: 7, No: 2, Hal: 111-125.

Komalasari, Zulianti. 2017. Pengaruh Locus Of Control Dan Komitmen Profesional Terhadap Kinerja Auditor Internal. Skripsi. Bandung. Program Pascasarjana (S1) Universitas Pasundan.

Luthans, F. 2005. “Organizational Behaviour 10th Edition”.Yogyakarta.ANDI. Mahdy, Emiral. 2012. Analisis Pengaruh Locus Of Control Dan Kompleksitas Tugas Audit Terhadap Kinerja Auditor Internal (Studi Pada Auditor Internal Pemerintah Yang Bekerja Pada Inspektorat Provinsi Jawa Tengah). Skripsi. Semarang. Program Pascasarjana (S1). Universitas Diponegoro.

Mangkunegara, Anwar Prabu. 2010. Perilaku dan Budaya Organisasi. Bandung : PT.Refika Aditama.

Nurmatias, Faizal. 2015. Pengaruh Etika Kerja Islam, Komitmen Organisasi Terhadap Kinerja Karyawan Di Institut Agama Islam Tafaqquh Fiddin Dumai. Jurnal Tamaddun Ummah, Vol: 01, No: 1, Hal: 1-14.

Panjaitan, Anton dan Bambang Jatmiko. 2014. Pengaruh Motivasi, Stres, Dan Rekan Kerja Terhadap Kinerja Auditor (Studi Empiris Pada Kantor Akuntan Publik Di Dki Jakarta). Jurnal Bisnis dan Ekonomi, Vol: 5, No: 1, Hal: 1-18.

Permana, Yockie. 2016. Analisis Pengaruh Motivasi, Stress, Dan Rekan Kerja Terhadap Kinerja Auditor Di Kantor Badan Pengawas Keuangan Dan Pembangunan Riau Dan Sumatera Utara. Jurnal Online Mahasiswa Fakultas Ekonomi, Vol: 3, No: 1, Hal: 13501364.

Putra, I Gusti Agung Mahendra dan Made yenni Latrini. 2016. Pengaruh Locus Of Control dan Komitmen Profesional Pada Kinerja Auditor Internal. E-Jurnal Akuntansi Universitas Udayana, Vol: 17, No: 3, Hal: 1808-1833.

Rahmawati dan Halim Usman. Pengaruh Beban Kerja Dan Pengalaman Auditor dalam Mendeteksi Kecurangan. Journal of Accounting and Investment, Vol:15, No.1, Hal: 6876.

Rahmawati, Zikra Supri. 2019. Audit internal dan Pendeteksian Kecurangan.Palopo : LPPI UM Palopo.

Saputra, komang adi kurniawan. 2012. Pengaruh Locus Of Control Terhadap Kinerja Dan Kepuasan Kerja Internal Auditor Dengan Kultur Lokal Tri Hita Karana Sebagai Variabel Moderasi. Jurnal Akuntansi Multiparadigma, Vol: 3, No: 1, Hal: 1-160.

Sari, Besse Mardiah. 2016. Faktor-Faktor Yang Mempengaruhi Kinerja Inspektorat Sebagai Internal Auditor (Studi Kasus pada Inspektorat Kabupaten/Kota seLuwu Raya). Skripsi. Makassar. Program Pascasarjana (S1). Universitas Hasanuddin Makassar.

Shauqi, achmad. 2018 . Analisis Pengaruh Locus Of Control Dan Kompleksitas Tugas Audit Terhadap Kinerja Auditor Internal (Studi pada Auditor Internal Pemerintah yang bekerja pada Inspektorat Se-Luwu Raya. Skripsi. Palopo. Program Pascasarjana (S1). STIE Muhammadiyah Palopo.

Widyastuti, Nurul. 2017. Pengaruh Pengalaman Audit Dan Locus Of Control Terhadap Perilaku Auditor Internal (Studi Empiris Pada Auditor Pemerintah Yang Bekerja Di Inspektorat Provinsi Sulawesi Selatan). Skripsi. Makassar. Program Pascasarjana (S1). Universitas Hasanuddin Makassar. 